\title{
A produção de subjetividades no contexto do capitalismo contemporâneo: Guattari e Negri
}

Fabio Montalvão Soares ${ }^{\star}$

Universidade Federal do Rio de Janeiro, Rio de Janeiro, RJ, Brasil

\section{Resumo}

Este artigo visa traçar um panorama sobre a relação entre a produção de subjetividades e a política no cenário atual, tendo por referência a leitura das obras de Félix Guattari, Antônio Negri e Michael Hardt sobre o tema. A partir da constatação do estatuto ontológico e coletivo inerente aos processos de subjetivação, busca-se pensar suas implicações no contexto do capitalismo contemporâneo, destacando suas principais características, o movimento de captura a fim deste se apropriar da produção de subjetividades em sua gênese e as possibilidades de resistência pelos autores esboçada, propondo a elaboração de novas estratégias para o enfrentamento do problema.

Palavras-chave: subjetividade; tempo; capitalismo contemporâneo.

\section{The production of subjectivity in the context of contemporary capitalism: Guattari and Negri}

\begin{abstract}
This article aims to give an overview on the relationship between the subjectivity production and politics in the current scenario, referring to the works of Félix Guattari, Antonio Negri and Michael Hardt on the subject. From the discovery of the ontological and collective status inherent in the subjectivity processes, we seek to think their implications in the context of contemporary capitalism, highlighting their main characteristics, the motion of capture in order to appropriate the production of subjectivities in its genesis and the possibilities of resistance outlined by the authors, by proposing the development of new strategies to face the problem.
\end{abstract}

Keywords: subjectivity; time; contemporary capitalism.

\section{Introdução}

Em 1986, Félix Guattari afirma em Micropolitica: cartografias do desejo, livro escrito em companhia de Suely Rolnik na época de sua visita ao Brasil, sua concepção de subjetividade como sendo um processo eminentemente coletivo e político, composto por uma diversidade de vetores, para além de um eixo organizador vinculado a uma instância psicológica, ou fundado na lógica da representação. Herdeiro de uma tradição psicanalítica, Guattari desponta como um pensador profundamente implicado na militância política. Fato que o leva a construção de uma profunda crítica aos preceitos vigentes, tanto da psicanálise, quanto do marxismo em sua expressão materialista na época (ZAMBONI; BARROS, 2012). Nos chama a atenção nos escritos de Guattari e em sua própria vida militante, seu posicionamento em relação à indissociabilidade entre a subjetividade e a política e sua crítica ferrenha ao capitalismo. Segundo sua concepção este já assumira uma perspectiva global, em sua condição de mundial e integrado, tal como apontava em 1977 em Revolução molecular: pulsações políticas do desejo. A proposta deste artigo é justamente a de refletir no contexto atual, sobre o modo de funcionamento do capitalismo contemporâneo e a produção de subjetividades, considerando-a em seu estatuto heterogêneo e ontológico, a partir dos textos de Guattari e associando-o com o que o pensamento ^Endereço para correspondência: Instituto de Psicologia da Universidade Federal do Rio de Janeiro. Programa de Pós-Graduação em Psicologia. Av. Pasteur, 250 - fundos. CEP: 22290-902 - Praia Vermelha - Rio de Janeiro, RJ, Brasil. E-mail: fabiocinemascope@gmail.com político contemporâneo vem assinalando sobre o tema, principalmente a obra de Antônio Negri e Michael Hardt. Também estes pensadores estabelecem uma concepção de subjetividade que se baseia num primado coletivo, sendo fundamento do que denominam poder constituinte (NEGRI, 1992), ou poder da multidão (HARDT; NEGRI, 2000). Neste sentido, identificamos a atualidade e a pertinência de uma crítica ao modo de funcionamento do capitalismo contemporâneo e a captura dos processos de subjetivação por este engendrada.

\section{Uma concepção ontológica de subjetividade: heterogeneidade e coletividade}

No texto "Subjetividade e História" de Micropolítica: cartografias do desejo, Guattari afirma que: "a subjetividade não é passível de totalização ou de centralização do indivíduo" (GUATTARI; ROLNIK, 1986, p. 31). Felix a define como indissociavelmente vinculada ao plano do desejo, enquanto materialidade de onde emanam e sustentam-se as produções coletivas. Os processos de subjetivação realizam-se, portanto, por intermédio de componentes heterogêneos, de materiais distintos, de linhas e vetores diversos relativos às existências, onde seus movimentos próprios caracterizamse como devires múltiplos que se atravessam num plano infinito de conexões e agenciamentos. Neste aspecto, não se trata somente de uma leitura sobre os fatores biológicos, ou da dinâmica psíquica envolvida em tal produção. Trata-se também, de fenômenos que dizem respeito à política, ao Estado, as tecnologias, bem como ao espaço 
urbano, aos meios de comunicação, a vida cotidiana e as mais variadas formas de agenciamentos indicativos das multiplicidades e dos diversos fluxos sociais:

Os processos de subjetivação [...], não são centrados em agentes individuais (no funcionamento de instâncias psíquicas, egóicas, microssociais), nem em agentes grupais. Esses processos são duplamente descentrados. Implicam o funcionamento de máquinas de expressão que podem ser de natureza extrapessoal, extraindividual (sistemas maquínicos, econômicos, sociais, tecnológicos, icônicos, ecológicos, etológicos, de mídia, enfim, sistemas que não são imediatamente antropológicos), quanto de natureza infra-humana, infrapsíquica, infrapessoal (sistemas de percepção, de sensibilidade, de afeto, de desejo, de representação, de imagens, de valor, modos de memorização e de produção idéica, sistemas de inibição e de automatismos, sistemas corporais, orgânicos, biológicos, fisiológicos, etc) (GUATTARI; ROLNIK, 1986, p. 31).

Não podemos incorrer numa leitura ingênua sobre a noção de subjetividade do autor, considerando-a, por exemplo, como algo que comporte de tudo um pouco, numa espécie de bricolagem de elementos gerais. $\mathrm{Na}$ verdade, Guattari chama a atenção para o fato de que a produção de subjetividades é indissociável de uma multiplicidade de vetores que se atravessam constante e incessantemente. Torna-se claro que ela se manifesta na própria constituição desses vetores, ao invés de simplesmente advir deles, não sendo, portanto, produto de uma instância individual. Não é a subjetividade que emerge de uma singularidade do sujeito e sim este, a própria vida e o mundo que se encontram nela mergulhados. Tal concepção se alinha com a afirmação de uma condição ontológica da subjetividade pensada antes como Diferença (DELEUZE, 1968), sendo puro devir, solo pulsante que faz variar todo esse plano de multiplicidades. A novidade é justamente a descentralização da noção de subjetividade, antes comumente considerada um produto exclusivo de uma instância psíquica ou individual, em favor de uma perspectiva coletiva: "Penso, ao contrário, que é a subjetividade individual que resulta de um entrecruzamento de determinações coletivas de várias espécies" (GUATTARI; ROLNIK, 1986, p. 340). E se partimos da proposição de que a subjetividade não é um produto de uma individualidade, não podemos entender a coletividade afirmada por Guattari simplesmente como um conjunto de indivíduos reunidos. ${ }^{1}$ A coletividade diz respeito à própria heterogeneidade de vetores que a compõe. Ou seja, a multiplicidade das infinitas linhas, dos devires moleculares que se atravessam, se imbricam, se entrelaçam e se agenciam, compondo as formas molares no plano da experiência concreta.

\footnotetext{
Esta é a concepção usualmente adotada nos estudos sobre política, tal como, por exemplo, por Hanna Arendt. Embora o poder seja traduzido em termos de coletivo, ele não expressa o sentido que damos ao termo, pois diz respeito ao conjunto de singularidades pensadas em termos individuais (o exemplo da dor física como subjetividade radical é proposto pela autora). O poder não é propriedade de um indivíduo, mas pensado como capacidade de agir em comum acordo. Ele pertence a um grupo, mas este, no sentido de nossa objeção, nada mais é do que um conjunto de singularidades individuais orientadas num pacto de renúncia do governo de si. Sobre o conceito de poder citamos: "Poder corresponde à capacidade humana de não somente agir, mas de agir em comum acordo. O poder nunca é propriedade de um indivíduo; pertence a um grupo existe somente quando o grupo se conserva unido" (ARENDT, 1969, p. 123).
}

\section{Produção de subjetividades e o Capitalismo Mundial Integrado}

A concepção ontológica e coletiva dos processos de subjetivação proposta por Guattari evidencia ainda mais a relação deste tema com a política, surgindo daí a necessidade de pensá-lo em suas implicações com o regime capitalístico. Não é à toa a sua afirmação de que no cenário contemporâneo a subjetividade é bem mais valiosa do que o petróleo (GUATTARI; ROLNIK, 1986, p. 26). O autor realiza uma crítica à exacerbação do materialismo na discussão contemporânea sobre o marxismo, em detrimento da subjetividade e afirma que os marxistas e progressistas não compreenderam a importância da discussão deste tema, pelo fato de se apegarem ao dogmatismo teórico. É importante notar que na apresentação do capítulo, o autor propõe uma concepção de subjetividade de natureza industrial/ maquínica: "Ou seja, essencialmente fabricada, modelada, recebida, consumida" (GUATTARI; ROLNIK, 1986, p. 25). Afirma-se de modo curioso e paradoxalmente neste texto, uma produção de subjetividades em escala industrial regida pela lógica de funcionamento capitalista em escala internacional: "A ordem capitalística produz os modos das relações humanas até em suas representações inconscientes: os modos como se trabalha, como se é ensinado, como se ama, como se trepa, como se fala, etc" (GUATTARI; ROLNIK, 1986, p. 42). O autor vislumbra uma estranha relação entre os processos de subjetivação e o modo de funcionamento do sistema capitalista, afirmando que o segundo cada vez mais se entrelaça ao primeiro e que, ao contrário dos marxistas e progressistas, este procurou cada vez mais investir nesse novo nicho, expropriando-o e lhe impondo ostensivamente uma lógica de correlação de valor. ${ }^{2}$ Daí o entendimento de que o capitalismo promove como sua principal estratégia de expansão, a captura dos processos de subjetivação.

Em Revolução molecular, Guattari (1977) já afirmava que o capitalismo mundial integrado - CMI opera por uma ostensiva miniaturização dos meios, indo bem além dos maquinismos técnicos. "O capitalismo se apodera dos seres humanos por dentro" (GUATTARI, 1977, p. 205), operando na base dos comportamentos perceptivos, sensitivos, afetivos, cognitivos, linguísticos, dentre outros. A instância individual torna-se uma espécie de terminal consumidor das demandas artificialmente produzidas, ou industrializadas pelos dispositivos capitalistas: "esse terminal individual se encontra na posição de consumidor de subjetividade" (GUATTARI; ROLNIK, 1986, p. 32). Em As três ecologias, Guattari (1989a, p. 30-31) reafirma esta relação entre capitalismo e subjetividade, apontando que o CMI tende cada vez mais a descentralizar seus focos de poder, das estruturas de produção de bens e de serviços, para as estruturas produtoras de signos

${ }^{2}$ Em Revolução molecular (GUATTARI, 1977) o autor aponta, no capítulo referente ao Capitalismo Mundial Integrado - CMI, que a sua expressão econômica não depende unicamente de um sistema de signos monetários, bolsistas, etc. É antes uma categoria semiótica que se refere ao conjunto de níveis de produção e ao conjunto dos níveis de estratificação dos poderes. Neste sentido, não se refere somente aos seus produtos como forma de expressão monetário-econômica, mas aos próprios "bens de produção" (servomecanismos maquínicos) como meios nos quais a produção de subjetividades se realiza. Ver: GUATTARI (1977, p. 213). 
afirmativos da lógica das relações de poder vigente e de subjetividade, especialmente por meio de dispositivos de controle como as mídias, a informática, as produções técnico-científicas, dentre outras. Nas Cartografias esquizoanalíticas (GUATTARI, 1989b), destaca como os modelos de subjetivação escapam ao controle dos dispositivos de poder dominantes, embora o cenário sócio-histórico-político indique que a subjetividade se encontra hoje, "massivamente controlada por dispositivos de poder e saber que põem as inovações técnicas, científicas e artísticas a serviço das figuras mais retrógadas da sociedade" (GUATTARI, 1989b, p. 17). E contra o movimento de captura orquestrado pelo CMI, Guattari propõe uma revolução molecular, a criação de máquinas de guerra autogestivas que viabilizem e potencializem os devires minoritários e os micromovimentos que subvertem os regimes molares já estratificados. Trata-se da afirmação de um plano instituinte em contraposição ao regime instituído; da possibilidade de se investir na própria subjetividade como estratégia de resistência ao modo de funcionamento do capitalismo. Esse fato nos conduz à necessidade de um mapeamento sobre como o tema dos processos de subjetivação vem se configurando no cenário atual. Torna-se, portanto, pertinente uma leitura, tanto sobre o modo de funcionamento do capitalismo na atualidade, quanto da própria concepção de um estatuto coletivo da subjetividade no campo político, o que nos aproxima das discussões propostas por Antonio Negri e Michael Hardt, no cenário contemporâneo.

\section{Negri e Hardt: Poder constituinte e as potências da multidão}

Em 1992, Antônio Negri publica $O$ poder constituinte, obra que irá tratar da consolidação de um plano político fundado numa ontologia do tempo como base dos processos coletivos e revolucionários, cunhando seus conceitos de Poder Constituinte e Multidão. Em 2000a, Negri publica ainda o livro Kairòs, Alma Vênus, Multitudo: nove lições ensinadas a mim mesmo, no qual se dedica ao trabalho sobre o conceito de Kairòs, signo/potência da irrupção revolucionária de uma temporalidade pura e libertária. Lança assim, as bases para o desenvolvimento de uma teoria política afirmativa de uma proposição coletiva, como opção na construção de estratégias de enfrentamento ao processo de captura engendrado pelas entidades denominadas transcendentais, ${ }^{3}$ dentre elas o Estado e o próprio

\footnotetext{
${ }^{3}$ Uma observação importante em relação ao termo transcendência: ele é tomado na obra de Negri e Hardt (2000), a princípio, como símbolo de um absoluto, ou universal, tal como, por exemplo, evocado na tradição kantiana, na Estética Transcendental em Crítica da Razão Pura. E é neste sentido que os autores se apropriam do termo para definir o Estado e o próprio capital como supostas entidades absolutas. No entanto, os autores se aproximam da tese deleuziana, na qual a Diferença não se reduz a nenhuma determinação, sendo ela mesma o a priori na figura da temporalidade pura do Devir. Se existe uma transcendência ou uma essência para Deleuze (1968), esta se exprime como a própria Diferença e o seu movimento intrínseco de diferir. Tal posição também se aplica a concepção do tempo de Kairòs como essência da multidão. Entretanto, se existe a transcendência da multidão por direito, existe ainda o uso arbitrário da ideia de transcendência de fato, tal como os autores a pensam no contexto do surgimento da modernidade. Ela seria assim, remetida segundo a tradição racionalista, a algo uno, ao homogêneo e ao universal. Logo, a transcendência, nesta parte da obra de Hardt e Negri, revela o movimento contrarrevolucionário de captura do poder constituinte e da multidão como signos do plano revolucionário de imanência. O termo visa refletir a imposição de princípios/tabus inquestionáveis, como eixos de justificativa da soberania moderna. Ver: Hardt e Negri (2000, p. 87-109). Sobre a transcendência, ver Deleuze (1968, p. 63-125).
}

capitalismo contemporâneo. Segundo o autor, o poder constituinte, não se caracteriza como a produção de normas constitucionais ou de um novo ordenamento jurídico regulador das relações sociais. Ele não emana simplesmente do Estado, mas se configura como o processo pelo qual a vontade democrática da multidão entrou no sistema político, debilitando os fundamentos constitucionalistas (NEGRI, 1992, p. 21). A multidão obviamente não equivale a um conjunto de indivíduos ou a conceitos que primam por unificar e homogeneizar as diferenças que lhe caracterizam, tais como povo, turba, massa, plebe, dentre outros, embora se relacione com essas entidades. Em parceria com Michael Hardt, o autor a definirá posteriormente em Multidão: guerra e democracia na era do império (HARDT; NEGRI, 2004), como um conjunto de singularidades, "um sujeito social cuja diferença não pode ser reduzida à uniformidade, uma diferença que se mantém diferente" (HARDT; NEGRI, 2004, p. 139). Também é esta a definição do autor em Cinco lições sobre o Império (NEGRI, 2000b). Ou seja, a multidão como plano das singularidades se afirma como eminentemente revolucionária e democrática, sendo $\mathrm{o}$ fundamento do poder constituinte:

O poder constituinte se define emergindo do turbilhão do vazio, do abismo da ausência de determinações como uma necessidade totalmente aberta. É por isso que a potência constitutiva não se esgota nunca no poder, nem a multidão tende a se tornar totalidade, mas conjunto de singularidades, multiplicidade aberta. $\mathrm{O}$ poder constituinte é essa força que se projeta para além da ausência de finalidade, como tensão onipotente e crescentemente expansiva. (NEGRI, 1992, p. 26).

Cabe salientar que, por não representar um conjunto de indivíduos, um arranjo grupal ou qualquer forma de representação, o poder constituinte se caracteriza pela ausência de qualquer determinação. E a singularidade não é singularidade de um. Não se trata de um diferente como resíduo exclusivo de um ente, mas da Diferença em si mesma como pura qualidade. A multidão como expressão da potência constitutiva está assim presente nessas instâncias e nelas manifesta-se sem, no entanto, reduzirse a elas. Trata-se da afirmação de um plano de potências intensivas, antes mesmo de pensarmos nas formas nas quais estas venham a se materializar no campo social. E não podemos deixar de pensar nesse plano como sendo da ordem de uma coletividade. A Multidão, portanto, abarca todas as manifestações, humanas e não humanas, podendo compreender fenômenos psicológicos, sociais, do Estado, tecnológicos entre outros. Ela implica desse modo, uma dimensão de heterogênese, compondo-se por uma multiplicidade de linhas de força, mas sem limitarse a elas. É importante enfatizar que o poder constituinte comporta uma dimensão subjetiva não localizável, nem mesmo nos microdevires moleculares que por ventura lhe componham, mas naquilo que se desvia das determinações e finalismos.

Num continuum as teses de $O$ poder constituinte, Negri em parceria com Hardt publica Império (2000), destacando-se o movimento instituinte dessas 
forças revolucionárias no contexto do surgimento da modernidade. Segundo os pensadores, instaura-se nesse momento, uma revolução radical, estabelecendo-se um novo paradigma de vida. "Nessas origens da modernidade, portanto, o conhecimento passou do plano transcendente para o plano imanente e, por conseguinte, esse conhecimento humano tornou-se um fazer, uma prática de transformar a natureza". (HARDT; NEGRI, 2000, p. 90). O plano de imanência ora citado é para os autores, aquele no qual as potências da multidão manifestam-se, na instauração permanente do poder constituinte.

O plano de imanência é aquele no qual os poderes da singularidade são realizados e aquele no qual a verdade da nova humanidade é determinada histórica, técnica e politicamente. Por esse fato único, por não haver qualquer mediação externa, o singular é apresentado como multidão (HARDT; NEGRI, 2000, p. 91).

Sendo assim, ele é o berço de toda metamorfose, pura variação e transformação constantes, caos revolucionário que se exprime em sua dimensão mais espetacular nas manifestações coletivas. As potências da multidão adquirem nesse momento, verdadeiro estatuto ontológico, afirmando-se como característica da era moderna nascente. Porém, diante dessa revolução radical, surge um movimento contra revolucionário que procurou dominar e expropriar a força dos movimentos emergentes:

Este é o segundo modo da modernidade, construído para combater as novas forças e estabelecer um poder para dominá-las. Ele surgiu [...] para alterar sua direção, transplantar a nova imagem de humanidade para um plano transcendente, relativizar a capacidade da ciência para transformar mundo, e acima de tudo, opor-se à reapropriação do poder pela multidão (HARDT; NEGRI, 2000, p. 92).

Trata-se, no cenário da modernidade e no processo de afirmação do capitalismo, da imposição de um poder constituído transcendente em oposição a um poder constituinte imanente. "Ordem versus desejo". A força constituinte relativa à multidão passa a ser contida e estratificada por um poder constituído, que procura se legitimar segundo valores de uma pretensa racionalidade expressa num cientificismo iluminista/positivista, cujo solo epistemológico baseia-se no princípio da representatividade como característica fundamental do Estado. Daí os autores o definirem como transcendental, em função deste ser um princípio preestabelecido e se impor dogmaticamente como universal. De acordo com essa perspectiva, o Estado teria por função garantir a organização e a gestão dos conflitos e dos interesses individuais, baseando-se na lógica hobbesiana da representação política, ou seja, na renúncia de um governo de si mesmo em favor de uma cívitas. ${ }^{4}$ Tal lógica se expressa e se aprofunda no plano jurídico, no confronto e no confinamento da potência constituinte em uma estrutura constitucional, definida falsamente

${ }^{4}$ Hobbes $(1999$, p. 144) afirma: "A única maneira de instituir tal poder comum [...] é conferir toda sua força e poder a um homem ou assembleia de homens, que possa reduzir suas diversas vontades, por pluralidade de votos, a uma só vontade. [...] Cedo e transfiro o direito de governar-me a mim mesmo, a este homem ou assembleia de homens [...]. Feito isso, a multidão assim unida numa só pessoa se chama Estado, em latim, cívitas". Trata-se da abdicação do governo de si a favor de um princípio de representatividade transcendente como base do Estado. como fonte da legitimidade de um Estado representativo, através do processo jurídico-normativo implícito nas relações contratuais: "O poder constituinte deve ser reduzido à norma de produção do direito e interiorizado no poder constituído _ sua expressividade não deve se manifestar a não ser como norma de interpretação, como controle de constitucionalidade, como atividade de revisão constitucional" (NEGRI, 1992, p. 10). Afirmase assim, a pseudolegitimidade deste poder constituído. Uma vez estabelecido ele procura afastar a coletividade daquilo que mais a caracteriza, ou seja, a sua potência constitutiva relativa ao plano de imanência, as forças da multidão: "O desafio básico deste iluminismo foi dominar a ideia de imanência sem reproduzir o dualismo absoluto da cultura medieval, construindo um maquinismo transcendental capaz de disciplinar uma multidão de sujeitos formalmente livres" (HARDT; NEGRI, 2000, p. 96). Por conseguinte, o Estado surge como primeira manifestação deste maquinismo dito transcendental, como aparato de captura da multidão.

\section{A subjetividade e seu estatuto ontológico: o Kairòs}

Para além do homem, as singularizações operadas fora dele e através dele, constituem uma potência de ilimitação, neste caso, cerceada pela instituição de um princípio considerado universal. Devemos enfatizar que os acordos, pactos e contratos balizados por tal princípio surgem não a priori, como resolução, mas a partir dos próprios conflitos e tensionamentos relativos às relações de poder. Os pactos e acordos são agenciamentos, produzidos no conflito, no embate entre as potências da multidão e não como mediações de uma instância supostamente transcendental, sendo este o princípio, segundo os autores, de uma democracia revolucionária. Da constatação da existência de uma dimensão heterogênea como uma das características da multidão, partimos para a discussão sobre o estatuto ontológico da subjetividade nos escritos de Negri. E ele se afirma principalmente na estreita relação entre o poder constituinte e o tempo, sendo este o motor dos processos revolucionários:

O poder constituinte tem sempre uma relação singular com o tempo. Com efeito, o poder constituinte é por um lado, uma vontade absoluta que determina o seu próprio tempo [...]. Mas isto não basta: o poder constituinte representa igualmente uma extraordinária aceleração do tempo. [...] Sob este ponto de vista, o poder constituinte está estreitamente ligado ao conceito de revolução (NEGRI, 1992, p. 22).

Devemos enfatizar que esta aceleração implica uma contração irresistível do tempo cronológico (presente, passado e futuro) na singularidade de um acontecimento único e extraordinário que o retira do seu eixo. Trata-se da qualidade do tempo no instante, como movimento de variação, ruptura e abertura, afirmação de um presente fugidio e que se torna singular. Tal tese é melhor contemplada na imagem do Kairòs. Para Negri (2000a), ela é o signo dessa temporalidade pura, fundamento da multidão e do poder constituinte. Ela é, na concepção clássica, o presente, momento singular de cisão, de ruptura e de abertura para um novo estado de coisas: "Kairòs é a 
modalidade do tempo através do qual o ser se abre, atraído pelo vazio que está no limite do tempo, e decide preencher este vazio" (NEGRI, 2000a, p. 43). Neste sentido, a vida se apresenta como um verdadeiro campo heterogêneo e nela se manifesta a multidão, potência de ilimitação que escapa ao instituído e a subjetividade se encontra no cerne da discussão sobre o poder Constituinte. Para Negri (2000a, p. 80), ela é a temporalidade em sua forma mais pura, potência disruptiva em sua afirmação mais radical: "A subjetividade, não subsiste, mas é produzida pelo Kairòs". Ela é, portanto, produto de uma temporalidade desmedida, ${ }^{5}$ sendo próprio fundamento da multidão e do político. As potências da multidão são signatárias desse estatuto e o seu fundamento político é caracterizado por esse regime de uma temporalidade considerada intempestiva, insubordinável ao tempo cíclico. Ao afirmarmos o advento de um plano de imanência e das multiplicidades, primamos pela compreensão de o imperativo deste fundamento ontológico ser a condição desta intempestividade do Kairòs como solo da produção das singularidades.

\section{Sobre o capitalismo Contemporâneo}

Desvendar o modo de funcionamento do capitalismo contemporâneo equivale a compreender a apropriação que este realiza do plano das singularidades ou da produção de subjetividades, entendido em nossa discussão como verdadeira potência de ilimitação e cuja estratégia de produção contraria a vertente de captura. Tanto Guattari quanto Negri se esforçam por demonstrar como se dá esse movimento, esboçando propostas alternativas de resistência a ele. Porém, frente às singularidades relativas ao plano de imanência, o capital também se consolida como uma nova figura considerada transcendental. Como nos mostra Neves (2002), ao tentar se apoderar dos seres humanos por dentro, ele busca se personificar como um verdadeiro "empreendedor ontológico". Mas o que se encontra em jogo efetivamente nesta operatória? É importante observar que o próprio Estado assume na atualidade, uma função secundária em favor do capitalismo globalizado. $\mathrm{Na}$ verdade, ele continua servindo como eixo organizador das relações através da normatividade jurídica. Mas se até aqui ele se supunha transcendental, o imperativo da expansão capitalista (desdobrada nos dispositivos de controle baseados na volatilidade do capital financeiro) assumiu proporções tão gigantescas, que acabou por tornar inviável a função reguladora do Estado sobre a movimentação desse capital volátil. Guattari (1977) já havia assinalado essa transição, de um regime sedentário e regionalizado para um sistema apoiado na dinâmica de mecanismos flexíveis no contexto macro e micro social, como característica do CMI. Autores como Gilberto Dupas (1999) afirmam, por exemplo, que os Estados nacionais têm encontrado óbvios limites em relação a sua atuação, sendo este um sintoma

${ }^{5}$ A desmedida se encontra na própria afirmação insurgente do poder constituinte. Se considerarmos o instituído, o estabelecido como um sistema fechado, nele a desmedida se impõe como necessidade de abertura. Em relação ao tempo, Chronos se fecha e se espacializa como medida do tempo e um tempo medida. Entretanto, o acontecimento escapa sempre a qualquer formalização. Ele se torna assim uma desmedida, aquilo que desequilibra, que subverte. Como nos mostra o autor na exposição desta temporalidade usando como exemplo o paradoxo do arqueiro: "o tempo é, na flecha que o constitui, a 'desmedida' entre aquele antes e este depois" (NEGRI, 2000a, p. 70). da nova fase do capitalismo. E mais desastrosa ainda para a pretensa transcendentalidade do Estado, é a pressão que este ordinariamente sofre para reduzir suas atribuições, a fim de que seu território representado possa desfrutar dos investimentos do mercado global. "Em certa medida, os Estados não têm hoje outra alternativa senão tentar atrair as transnacionais, de forma a garantir empregos e receitas ao país" (DUPAS, 1999, p. 130). O Estado transforma-se numa espécie de refém do mercado de capitais, figurando mais como um dispositivo de controle, repressão e exclusão a serviço do sistema capitalista. Ele torna-se verdadeiramente sua agência reguladora. $\mathrm{Na}$ verdade, estamos diante de uma transformação nos modos de acumulação próprios do capitalismo. David Harvey (1990) analisa as transformações ocorridas no modo de produção capitalista a partir dos anos setenta por intermédio do que ele conceitua como regime de acumulação. Este "descreve a estabilização, por um longo período, da alocação do produto líquido entre consumo e acumulação; ele implica alguma correspondência entre a transformação, tanto das condições de produção como da reprodução dos assalariados" (HARVEY, 1990, p. 118). Sua descrição é baseada na transição entre o regime de acumulação característico do modelo fordista para o modelo contemporâneo da "acumulação flexível". E a transição para esse novo modelo teria como uma de suas condições, a descentralização do papel do Estado na regulação dos processos econômicos:

Hoje, o Estado está numa posição muito mais problemática. É chamado a regular as atividades do capital corporativo no interesse da nação e é forçado, ao mesmo tempo, [...], a criar um "bom clima de negócios", para atrair o capital financeiro transnacional e conter [...] a fuga de capital para pastagens mais verdes e mais lucrativas (HARVEY, 1990, p. 160).

Oque desejamos demonstraré quenocontemporâneo, o capital, em detrimento do Estado, torna-se o novo transcendental. E o fenômeno da globalização nos indica ainda, a formação de uma nova ordem mundial baseada em um novo modelo de soberania. Hardt e Negri (2000) a definirão como "Império", uma ordem para além dos Estados constituídos: "Nossa hipótese básica é que a soberania tomou nova forma, composta por uma série de organismos nacionais e supranacionais, unidos por uma lógica ou regra única. Essa nova forma global de economia é o que chamamos de Império" (HARDT; NEGRI, 2000, p. 12).

No contexto da formação de uma nova ordem global imperial, há uma significativa transformação nas relações de poder, que não se polarizam ou se modulam somente segundo o eixo gravitacional do Estado. Concomitantemente à sua condição secundária no plano regulatório das relações, registramos uma mudança no próprio eixo gravitacional. Isso implica uma total reconfiguração das relações políticas e de poder, pois o Estado perde sua antiga função. A política ganha nova conotação e amplia seu foco de atuação para além da Polis, dos Estados-Nação e dos territórios. Deparamo-nos no contemporâneo, com uma verdadeira deslocalização do político. E o poder constituinte da multidão nos leva a 
este entendimento, pois toda ação sendo oriunda de uma potência, ou conjunto de potências, torna-se eminentemente política. Por conseguinte, esta se vitaliza e se renova incessantemente, transpondo um lugar ou um domínio que lhe caracterize. Política é vida. Ela está na ordem das relações de poder e da produção de subjetividades. Tudo então passa a ser de interesse político, no sentido de uma autogestão da vida. Trata-se, portanto, da afirmação de um governo de si mesmo em contrapartida a instituição de uma cívitas. Para além do macro, as micropolíticas se originam no embate entre as potências da multidão. Mas o capitalismo, em suas múltiplas modulações, impõe à lógica da autorregulação das forças coletivas, um poder constituído em termos de um coletivo pensado como conjunto de indivíduos e consolidado na expropriação transcendental do contrato (comum acordo). Ele libera os fluxos inerentes à vida, com a condição de que estes se modulem a seu modo de funcionamento, impondo sua lógica como agencia reguladora.

Consequentemente, o capitalismo global, investindo sobre a vida em toda a sua generalidade, tende a se apropriar da produção de subjetividades na dimensão de sua temporalidade. Autores como Octávio Ianni (1995) afirmam, por exemplo, que a globalização investe fundamentalmente sobre o tempo e o espaço, modificando radicalmente nos últimos anos a forma de manipulá-los. O capital tenta, na verdade, se apropriar da vida em sua potência heterogênea de variação como produção. Sabemos que ele organiza essas duas instâncias no campo produtivo. Mas a discussão sobre esse assunto não se esgota, por exemplo, numa simples questão logística do espaço geográfico e da administração do tempo produtivo e de trabalho próprios à instalação de um complexo industrial transnacional, ou mesmo na transmigração deste complexo de uma região ou país para outro. As corporações podem atualmente ocupar minimamente o espaço de alguns andares em um arranha-céu em qualquer lugar do globo e investir num sistema virtual de representatividade de seu produto, desobrigando-se de investimentos em setores primários de produção: "uma das maiores fabricantes de tênis do mundo, não produz nenhum cadarço sequer" (DUPAS, 1999, p. 42). Mesmo nas grandes indústrias de base essa transmigração já se configura rotina. Uma imensa fábrica de automóveis ou uma siderúrgica podem facilmente mudar de localidade, bastando para isso lhes ser ofertada uma redução de carga tributária, ou que o valor de mão de obra numa outra região seja suficientemente atrativo. A globalização também produziu transformações sobre a movimentação dos fluxos financeiros. Eles circulam livremente de território em território, num continuum que, embora não dissolva, consegue transpor as fronteiras dos Estados-Nação subvertendo suas regulações. Tal flexibilização na transmigração dos bens de produção e do fluxo financeiro, nos indica uma mudança radical na relação com o tempo. Ele de certa maneira se acelera, segundo as determinações da lógica global. Graças ao desenvolvimento tecnológico, a produção se aperfeiçoa, produzindo-se mais em menos tempo. As transações financeiras também se beneficiaram dessa otimização. A tecnologia digital possibilita transações instantâneas entra as bolsas de valores e demais organizações financeiras; a internet e a tecnologia digital produziram uma incomensurável agilidade no processamento e circulação de informações, além de um eficaz sistema de controle e vigilância, alterando o panorama geopolítico do planeta.

Entretanto, há de se estabelecer nesse momento, uma diferença crucial em relação ao investimento sobre o tempo e o espaço por parte do capitalismo contemporâneo. Não se trata mais de uma simples organização destas categorias ou dos recursos delas oriundos. Desejamos enfatizar que a vida como produção se torna um fenômeno cuja essência é o próprio tempo. A questão não é mais a de organizar e controlar a produção sobre um tempo-espaço a priori. O próprio tempo, e consequentemente, o espaço tornam-se agora os verdadeiros agentes produtores. Todos os regimes de variabilidade seja esta física, biológica ou psicológica, se originam dele. O tempo é o cerne da vida como processo incessante de produção. Não é só o homem, sujeito da cultura, que produz e transforma a natureza. Já não se sustentam mais contradições como essas, e a natureza passa a ser vista como regime maquínico de produção, tal como nos afirmam Deleuze e Guattari (1966) em $O$ Anti-Édipo. Não devemos, portanto, nos referir à produção como nos sistemas econômicos tradicionais, interpretando-a como ação industriosa específica ao homem ou à cultura, mas à produção de produção:

O consumo e o registro determinam diretamente a produção, mas a determinam no seio da própria produção. De tal modo que tudo é produção: produção de produções, de ações e reações; produções de registro, de distribuições e de pontos de referência, produção de consumos, de volúpias, de angústias e de dores. Tudo é produção: os registros são imediatamente consumidos, destruídos, e os consumos diretamente reproduzidos (DELEUZE; GUATTARI, 1966, p. 09).

A vida se autotransforma. Ela se produz segundo um regime de variação inerente ao tempo. E o capitalismo global tende a investir nisso. Ele se expande sobre este novo registro da produção que é a própria vida e, para tal, tenta se apropriar do tempo como solo-fundação do regime de variabilidade. Desse modo, o capitalismo, em seu movimento de expansão, tenta se impor como o eixo organizador de toda e qualquer relação. É no tempo que o capital quer se plugar a todo custo, com unhas e dentes! Se defendermos a hipótese de que a vida tem seu fundamento constitutivo num regime especial de temporalidade, nossa investigação nos leva a crer que o capitalismo quer se apropriar dela em seu caráter ontogenético e por consequência, da potência de variação que lhe corresponde. Ao se apropriar da vida ele investe (no melhor sentido de um empreendedor voraz évido por um nicho de mercado potencialmente gerador de lucro) sobre essa potência. É deste modo que o capitalismo se torna eminentemente um empreendedor ontológico. Ele quer se infiltrar no ser das coisas, ser a imanência d'onde tudo flui. Daí sua aspiração transcendental. A hipótese é 
a de que o capitalismo sobrepõe à velocidade do tempo como devir, a aceleração de Cronos. Como afirma Guattari (GUATTARI; ROLNIK, 1986, p. 43): “A ordem capitalista incide nos modos de temporalização. Ela destrói os antigos sistemas de vida, ela impõe um tempo de equivalências, a começar pelo assalariamento, através do qual ela valoriza as diferentes atividades de produção".

\section{O tempo do capitalismo e a produção de subjetividades}

No âmago do poder constituinte, a contração do tempo cronológico num acontecimento instituinte nos indica a passagem a sua forma pura, assumindo a condição de potência criadora. Porém, lembremos que ela se opõe à aceleração de Cronos, característica do capitalismo. A primeira relaciona-se ao devir, gerando novos agenciamentos, novas formas, modos de ser e estar no mundo. Ela nada tem a ver a princípio, com a segunda, ordinariamente entendida como o tempo acelerado das conexões instantâneas do mercado de ações, ou o ritmo cada vez mais rápido de vida nos centros urbanos, como exemplos de uma suposta aceleração temporal. Neste último caso, estamos nos referindo ao tempo cíclico. Ele é efeito da captura do tempo no acontecimento. Pensar de outro modo, no plano político, a eminência de um tempo puro como fundamento da imanência e das singularidades que compõem a multidão, nos leva sem dúvida, a uma discussão sobre a produção de subjetividades que escape ao modelo de organização baseado num eixo transcendental. Como nos aponta Félix, "a produção de subjetividades pelo CMI é serializada, normalizada, e centralizada em torno de uma imagem, de um consenso subjetivo referido e sobrecodificado por uma lei transcendental" (GUATTARI; ROLNIK, 1986, p. 40). A subjetividade se encontra, portanto, no centro do embate entre o poder constituinte e o poder constituído representativo e legitimador do Estado regulador, pois se ela é singularidade, só pode assim se designar como expressão das potências da multidão, plena afirmação do poder constituinte como garantia democrática de sua "revolucionalidade". Consequentemente, apostar numa revolução constante como base do poder constituinte imanente, em contraposição ao poder constituído do Estado, é afirmar novos modos de singularização que sejam espontâneas manifestações desse poder, resistindo à captura ostensiva perpetrada pelas instituições e pelos diversos organismos que compõem o corpo social em seus mais variados dispositivos de controle.

A subjetividade constitui-se na singularidade de um tempo intempestivo. Não se trata simplesmente de uma singularidade atribuída a um sujeito, mas do desenrolar do tempo nos fenômenos relativos à vida, tida aqui como processo maquínico. Ou seja: as linhas se estratificam, se codificam e se sobrecodificam, mas a pulsão insistente relativa ao Kairòs produz desmedidas, desarranjos, variações, novas transmutações, produzindo novas formas de funcionamento. As máquinas desejantes inoculam a produção no produto. Por conseguinte, a produção diz respeito à pulsão de variação inerente à vida e cujo solo-fundação é o Kairòs, essência do poder constituinte. Tal é o cerne do plano de imanência. Logo, a produção de subjetividades é considerada questão central na geopolítica de expansão capitalista. Daí a importância monumental da discussão proposta por estes autores sobre o tema, delineando-se o movimento de sua captura engendrado pelo capitalismo globalizado contemporâneo, pois "o lucro capitalista é fundamentalmente, produção de poder subjetivo" (GUATTARI; ROLNIK, 1986, p. 32).

A expansão capitalista paradoxalmente, não investe mais somente em uma direção espacial como território externo ao sujeito. O que se desdobra é uma expansão para dentro, uma expansão que investe na contração do tempo cronológico e do espaço, no esforço de capturar seu elemento disruptor, o qual afirmamos ser o regime de temporalidade inerente à multidão. Trata-se de uma expansão no sentido do mínimo, ou singular. $\mathrm{O}$ capitalismo inverte a lógica de expansão, mergulhando na ínfima extensão da subjetividade, buscando se apropriar dela em sua gênese. Por isso, uma geopolítica dada em um regime molecular das relações de poder. Sua pseudo transcendentalidade se afirma por meio da subjugação de Kairòs a um poder constituído, segundo a nova lógica do capital. Hardt e Negri (2000) afirmam que um dos movimentos do novo poderio soberano imperial foi justamente o de sobrepujar os antigos binarismos segregatórios fundados, por exemplo, no princípio da dialética hegeliana como base de formação jurídica dos Estados-Nação. Na experiência do iluminismo existiam duas tradições distintas: a do humanismo renascentista, com a celebração da imanência, da singularidade (pensadas com Duns Scott e Spinoza, dentre outros); e a outra tradição racionalista, na busca do controle das forças da primeira tradição. O modo transcendental dialético dualista serviu por um longo período como princípio de organização dessas forças. Mas as transformações dadas no desenvolvimento da soberania global levaram a uma flexibilização das fronteiras e à abolição das dicotomias, num aparente movimento de reinvenção das instituições: "Os binarismos e dualismos da soberania moderna não são desorganizados apenas para que outros se estabeleçam. Ao contrário, o próprio poder dos binários é dissolvido quando fazemos as diferenças atuarem sobre fronteiras" (HARDT; NEGRI, 2000, p. 159). Nesse sentido, poderíamos afirmar que na nova ordem mundial, o capitalismo exalta a afirmação das diferenças, deixando transparecer apenas uma flexibilização das fronteiras antes rígidas na geopolítica das relações de poder. A estratégia deixa de ser a de rechaçar ou reprimir as diferenças e passa a ser a de distribuí-las em linhas limítrofes de organização e regulação: "Essas diferenças, é claro, não atuam livremente num liso espaço global, mas são de preferência arregimentadas em redes globais de poder, que consistem em estruturas altamente diferenciadas e móveis" (HARDT; NEGRI, 2000, p. 169). Portanto, não foram dissolvidas as fronteiras. Pelo contrário, a meta é fazer as diferenças atuarem sobre elas como dispositivos de regulação de conflitos. A diferença apregoada pelo capitalismo diz respeito à variação de um modelo numa medida, série ou padrão, que pode ser denominada como estrutura ou fronteira transcendental a priori. E se 
a Diferença como subjetividade ou temporalidade pura é o solo desmedido da variação da vida e da produção, o capitalismo em sua lógica expansionista tenta dela apropriar-se, regulando seu regime de variabilidade:

Circulação, mobilidade, diversidade e mistura são as condições que a tornam possível. O comércio junta as diferenças, e quanto mais, melhor! As diferenças (de mercadorias, de populações, de culturas e assim por diante) parecem multiplicar-se infinitamente no mercado mundial, que não ataca nada com tanta violência como as fronteiras fixas: ele esmaga qualquer divisão binária com as suas infinitas multiplicidades (HARDT; NEGRI, 2000, p. 168).

Trata-se efetivamente, de uma produção de subjetividades. Porém, de subjetividades capturadas. Se o poder constituinte nos impele ao caráter revolucionário da multidão como gênese das singularizações ou dos modos de existência, a contra revolução se caracteriza justamente pelo cerceamento desta potência. A estratégia do capitalismo contemporâneo consiste em capturar a potência revolucionária nela implícita, isto é, se apropriar da dimensão do tempo como fundamento da multidão. Uma vez efetivada a captura, a produção de subjetividades passa a se orientar segundo uma lógica dita transcendental, na qual a potência constituinte é expropriada num processo de ordenação temporal, numa normatividade transcendente preestabelecida. E é nesse sentido que o consideramos funestamente como um empreendedor ontológico.

\section{Capitalismo e controle}

Concluímos que o capitalismo paradoxalmente afirma seu funcionamento pela contínua apropriação, regulação e liberação dos fluxos inerentes à vida. É muito fácil acreditar que na atualidade alcançamos o auge do liberalismo. Tudo é permitido, contanto que se pague um preço alto. O preço é segundo Deleuze (1990), o controle. Este se caracteriza justamente por essa liberação dos fluxos na medida proporcional, estreita e direta de sua modulação à moeda corrente e ao fluxo monetário do mercado financeiro como expressão máxima da circulação de valores. A partir do momento em que a própria vida tornou-se um bem com seu correlato valor de uso e de troca, nada se deixa escapar a uma possível modulação num espectro em moeda. Consequentemente, todos os fenômenos da vida passam a ocupar as prateleiras do mercado, constituindo-se bens de consumo. A tendência, a princípio, é de que nada escape a esse novo regime de expansividade do capitalismo global. Este passa a se expandir explorando a potência de variação, e com isso lhe impondo ostensivamente uma correlação de valor. Deparamo-nos aqui com um embate micropolítico por excelência, pois se as potências da vida ou da multidão compõem o campo das práticas, tendo por base a coletividade, estas dizem respeito a um verdadeiro plano imaterial ou molecular. Plano heterogêneo de intensidades, de afetos, que se atravessam, se conectam, se modulam e produzem, em seus agenciamentos, os mais variados modos de existência. Por um lado, vemos o capitalismo em sua vertente de apropriação da vida a partir da instituição do controle como forma de captura. Por outro, os fenômenos de expansão da multidão indicam também um agenciamento potencializador da própria vida. Daí a proposição feita por Guattari de uma micropolítica como resistência às formas de dominação.

O capitalismo, em seu implacável movimento de expansão, busca expropriar o plano de imanência, produzindo o sucateamento das existências ao lhes impor uma forma de controle sobre os processos de subjetivação. Esta é a dificuldade de se tentar enfrentar a estratégia contra revolucionária imperial, pois a princípio, o empreendedor ontológico já percebe a produção como inerente não exclusivamente ao humano, mas à vida em sua totalidade. Ele se apropria da potência de vida como produção. Mas cabe sempre lembrar que as multiplicidades emergem na gênese e na metamorfose de uma produção eminentemente maquínica, centrada na singularidade dos acontecimentos, no devir. A produção se configura como um fenômeno da vida como um todo. Considerá-la como exclusiva ao homem ou ao sujeito da cultura que transforma a natureza, é a falácia transcendental que oculta o verdadeiro sentido do poder da multidão. Porém, a vida sempre escapa ao controle e nela a desmedida se impõe, subvertendo o estabelecido, o instituído. "Desejo versus ordem". Mas, se o capitalismo se apropria da potência de ilimitação não o faz pela sua limitação ou repressão, mas por sua plena exploração. Daí, a lógica de expansão capitalista se moldar à variação da vida enquanto sua principal característica. Da mesma maneira pela qual o poder constituinte é interiorizado pelo poder constituído, a variabilidade inerente à vida é interiorizada no regime de expansividade do capitalismo. Surge então, uma espécie de variação a partir do controle e ela diz respeito à submissão da potência de ilimitação a um pressuposto vetor como gênese e como organizador dessa variabilidade. Consequentemente, este assume o status de transcendental. E, considerando a tentativa do capitalismo de se apropriar da variação inerente à vida como produção, a grande inovação torna-se o fato deste não se configurar mais unicamente como doador de trabalho. Ao se apropriar da potência de variabilidade ele torna-se fundamentalmente doador de tempo. Ele canaliza os processos produtivos da vida como um todo e, em especial, se apropria da temporalidade como motor dessa produção, fazendo-os operar sob um princípio único. Ou seja, o capitalismo visa apropriarse da potência em sua gênese. Portanto, ele busca capturar o próprio tempo e se não consegue realizar integralmente esta façanha, tenta ao menos lhe impor um vetor de ordenação e organização, sobre o qual toda a variação deva fluir. Tal é a característica do capitalismo contemporâneo: o cerceamento da potência de ilimitação (fundamentada na dimensão do tempo relativo aos processos de subjetivação) se dá pela instituição de eixos transcendentais, organizadores de sua variabilidade. A operação consiste em deslocar para coadjuvante a mutabilidade própria ao tempo intempestivo, do acontecimento relativo ao Kairòs, submetendo-o a um tempo linear e cronológico como vetor de organização 
a priori de toda variação. O capitalismo torna-se doador de tempo na medida em que ele expropria o processo de produção inerente à vida. Ele desterritorializa os processos de subjetivação, fazendo-os reterritorializar segundo sua lógica estruturante. Desta maneira ele insiste em se apropriar da função do tempo nos fenômenos da produção de subjetividades.

\section{Concluindo: $O$ atrevimento de singularizar}

Investir na coletividade, na potência das multiplicidades, nos devires minoritários. Produzir em cada canto, revoluções moleculares nas quais a maior virtude seja a de suplantar os dispositivos de controle e escapar à lógica imposta pelo capitalismo contemporâneo: "É preciso que cada um se afirme na posição singular que ocupa; a faça viver, que a articule com outros processos de singularização e que resista a todos os empreendimentos de nivelação de subjetividade" (GUATTARI; ROLNIK, 1986, p. 50). Trata-se de afirmar a singularidade nela mesma como tal, de se apropriar daquilo que acontece em si e a partir de si mesmo. Governo de si ao invés de renúncia ou pactos de representatividade. Subjetividade insurgente versus poder imperial. Entretanto, afirmar as singularizações já não nos parece suficiente, uma vez que o próprio capitalismo também as afirma. E pior do que esse fato é o movimento estabelecido de se tragar qualquer mote de subjetivação divergente, de infiltrar-se nele por dento e corrompê-lo, impondo-lhe sorrateiramente sua lógica de valor e tornando-o mais um produto em sua prateleira de novidades prêt-à-porter. A fim de resistir a esse movimento Guattari insiste num investimento constante na coletividade. Não nos indivíduos ou grupos somente, mas principalmente na potência heterogênea que se afirma no plano de imanência como base das novas singularizações neles perceptíveis.

Mas como estabelecer movimentos divergentes, se o capitalismo já se instala no âmago do ser e se apropria do tempo? Negri (2000a, p. 148-149) conclui que a característica maior da multidão é o amor pelo tempo, amor pela singularidade naquilo que ela é, para além dos modos ou formas singularizadas. O que nos mostra o autor é justamente a falência dessa suposta apropriação. Os dispositivos jurídicos do Estado e do Capital já não dão mais conta da infinidade de acontecimentos que se deflagram no globo a todo instante, pasmem, potencializados muitas vezes pelos próprios dispositivos de controle que o capital tenta impor. Neste sentido, cabe a insistência no investimento no tempo da multidão como vetor de subjetivação: "Tempo é uma experiência coletiva que ganha corpo e vive nos movimentos da multidão" (HARDT; NEGRI, 2000, p. 425). Hardt e Negri (2000, p. 427-431) nos mostram que se trata de uma reapropriação da vida como produção e de uma posse, considerada em termos do que o corpo e a mente podem fazer. O contemporâneo se afirma assim como um novo momento de insurgência dos poderes da multidão. E ficamos, sob a inspiração de Guattari, com a mensagem final desses autores, de que a atitude por excelência é a do militante que resiste criativamente ao comando imperial na produção de novos modos de ser e estar no mudo, num movimento incessante de contágio.

\section{Referências}

DELEUZE, G. Diferença e repetição. São Paulo: Graal, 1968.

DELEUZE, G. Conversações. Rio de Janeiro: 34, 1990.

DELEUZE, G; GUATTARI F. O Anti-Édipo: capitalismo e esquizofrenia. Lisboa: Assírio \& Alvim, 1966.

DUPAS, G. Economia global e exclusão social: pobreza, emprego, estado e o futuro do capitalismo. São Paulo: Paz e Terra, 1999.

GUATTARI, F. Revolução molecular: pulsações políticas do desejo. São Paulo: Brasiliense, 1977.

GUATTARI, F. As três ecologias. Campinas: Papirus, 1989a.

GUATTARI, F. Cartografias esquizoanalíticas. Buenos Aires: Manantial, 1989b.

GUATTARI, F.; ROLNIK, S. Micropolítica: cartografias do desejo. Rio de Janeiro: Vozes, 1986.

HARDT, M.; NEGRI, A. Império. Rio de Janeiro: Record, 2000 .

HARDT, M.; NEGRI, A. Multidão: guerra e democracia na era do Império. Rio de Janeiro: Record, 2004.

HARVEY, D. A condição pós-moderna: uma pesquisa sobre a mudança cultural. Rio de Janeiro: Loyola, 1990.

HOBBES, T. Leviatã ou matéria, forma e poder de um Estado eclesiástico e civil. São Paulo: Nova Cultural, 1999.

IANNI, O. Teorias da globalização. Rio de Janeiro: Civilização Brasileira, 1995.

NEGRI, A. O poder constituinte: ensaios sobre as alternativas para a modernidade. Rio de Janeiro: DP\&A, 1992.

NEGRI, A. Kairòs, Alma, Vênus, Multitudo: nove lições ensinadas a mim mesmo. Rio de Janeiro: DP\&A, 2000a.

NEGRI, A. Cinco lições sobre o Império. Rio de Janeiro: DP\&A, 2000b.

NEVES, C. E. A. B. Interferir entre desejo e capital. 2002. 242 f. Tese (Doutorado)-Pontifícia Universidade Católica de São Paulo, São Paulo, 2002.

ZAMBONI, J.; BARROS, M. E. B. de. Um clínico da atividade desejante no campo social: Félix Guattari. Revista Polis e Psique, Vila Velha, v. 2, n. 1, p. 23-42, set./dez. 2012.

Recebido em: 1 de agosto de 2013 Aceito em: 24 de setembro de 2015 